\title{
Implant Surface Microtopography - A Review
}

\author{
Sunny Sharma ${ }^{1 *}$, Ginne Bharti ${ }^{2}$, Ramandeeep Singh ${ }^{3}$, Puneet Gupta ${ }^{4}$, Basu Dev Basnett ${ }^{1}$, Sonali Sharma ${ }^{3}$
}

\begin{abstract}
Osseointegration is the direct contact between the living bone and the implant surface without interposed soft tissue at the microscopic level and it is a critical process for implant stability and consequent short- and long-term clinical success. Surface conditions are particularly important as they play a major role in the osseointegration process. Several characteristics among implant surface, such as surface composition, physicochemical properties, surface wettability, and roughness influence the rate and quality of osseointegration. The goal of this review is to analyze the currently available methods for implant surface modification and also discuss the future trends in surface bioengineering and nanotechnology for improving the osseointegration and consequently their biological performance.
\end{abstract}

Keywords: Dental implants, Endosseous implants, Implant surface treatments, Microtopography, Surface coatings

Asian Pac. J. Health Sci., (2020); DOI: 10.21276/apjhs.2020.7.2.12

\section{INTRODUCTION}

Scientifically based implant therapy, emerged at the end of the 1970s following ground breaking studies with 10-year clinical results presented by a research group in Sweden directed by Dr. Branemark et $a l^{[1,2]}$ A published study showed that more than 220 implant brands are present globally producing more than 2000 different types of implants. ${ }^{[3]}$ Considering the variety of materials, surface treatments, shapes, lengths, and widths available, clinicians have a wide array to choose from them during treatment planning, but which one is to choose? Is still a question of concern? Following implantation, events take place both on the biological side and on the materials side. According to the "interface scenario" of Kasemo and Gold, ${ }^{[4]}$ primary molecular events lead to secondary events that ultimately result in particular cell and tissue responses. Development of interface is complex and involves numerous factors. ${ }^{[5]}$ These include not only surgical technique but also implant-related factors, such as material, shape, topography, and surface chemistry. To alter the surface characteristics to improve implant performance, much attention has been focused on changes in surface roughness and chemistry.

Smooth, polished surfaces show poor mechanical integration with bone because, without surface irregularities, these surfaces provide no resistance to mechanical forces at the bone-implant interface. ${ }^{[6]}$ Machine-finished implants, such as the Branemark System implants (Nobel Biocare, Zurich, Switzerland), have a substantial history of use, whereas they may appear macroscopically smooth, but the implants have a low roughness, in the range of $0.5-1 \mathrm{~mm}^{\left[{ }^{7]}\right.}$

Surface characteristics directly and indirectly influence the way of molecules present in the biological world act and this might ultimately control new tissue formation as cell proliferation and differentiation both depend on quality of early adhesion. ${ }^{[8]}$ Many research efforts have been directed toward improving the bone-implant interface, with the aim of accelerating bone healing and improving bone anchorage to the implant. ${ }^{[9]}$ The interface is improved physically by the architecture of the surface topography. At the micrometer level, the reasoning for this approach is that a rough surface presents a higher developed area than a smooth surface, and thus increases bone anchorage and reinforces the biomechanical interlocking of the bone with the implant, at least up to a certain level of roughness. At the nanometer level, the
'Department of Prosthodontics and Crown \& Bridge, Himachal Institute of Dental Sciences, Paonta Sahib, Himachal Pradesh, India

${ }^{2}$ MDS, Prosthodontics and Crown and Bridge, Jammu and Kashmir, India

${ }^{3}$ Department of Prosthodontics and Crown and Bridge, Bhojia Dental College, Baddi, Himachal Pradesh, India

${ }^{4} \mathrm{MDS}$, Orthodontics and Dentofacial Orthopaedics, Yammuna Nagar, Haryana, India

Corresponding Author: Dr. Sunny Sharma, Department of Prosthodontics and Crown and Bridge, Himachal Institute of Dental Sciences, Paonta Sahib, Himachal Pradesh, India. Email: sny87sharma87@gmail.com

How to cite this article: Sharma S, Bharti G, Singh R, Gupta P, Basnett BD, Sharma S. Implant Surface Microtopography - A Review. Asian Pac. J. Health Sci., 2020; 7(2):48-53

Source of support: Nil

Conflict of interest: None

Received: 15/04/2020 Revised:26/05/2020 Accepted:29/05/2020

roughness increases the surface energy, and thus improves matrix protein adsorption, bone cell migration and proliferation, and finally osseointegration. ${ }^{[10]}$

\section{Historical Background}

The history of evolution of dental implants is a rich and fascinating travelog through time. The first evidence of dental implant is attributed to the "Mayan" population roughly around 600 AD where they utilized pieces of shells as implants for replacement of mandibular teeth. ${ }^{[11]}$ In 1913, Dr. EJ Greenfield placed a 24-gauge hollow latticed cylinder of iridium-platinum soldered with $24-\mathrm{K}$ gold as an artificial root. ${ }^{[12]}$

In the 1940's, Formiggini and Zepponi developed post-type endosseous implant. Dr. Raphael Chercheve from France added to the spiral design by creating burs to ease the insertion of the implant for a best fit. Various implant designs expanded in the 1960's. ${ }^{[13]}$

In 1978, Dr. Branemark et al. presented a two-stage threaded titanium root-form implant. ${ }^{[14]}$ Two other ground-breaking persons of modern implantology were Dr. Schroder and Dr. Straumann of Switzerland. ${ }^{[15]}$ 


\section{Why There is Need of Surface Modification?}

It is widely accepted that the surface properties of a dental implant play a major role in the osseointegration process and biomechanical fixation due to its influence in the implant-tissue interactions as it affects directly the behavior of the surrounding tissues. ${ }^{[15-18]}$ The surface features become extremely important at the initial healing period of an implant as they influence directly the dynamics of the bone-implant interface and consequently command the short- and long-term success rate of the prosthetic treatment. The implant surface characteristics including topography, chemistry, surface charge, and wettability are likely to be of particular relevance to the chemical and biological interface processes in the early healing stages after implantation. ${ }^{[19]}$ Surface modifications influence cell proliferation and differentiation, extracellular matrix synthesis, local production factors, and even cell shape, gene expression, protein secretion, differentiation, and apoptosis. This will consequently affect retention and proliferation of osteogenic cells at the implant site. ${ }^{[20]}$

\section{Methods of Implant Surface Treatments}

Dental implant surface structure, morphology, and chemistry can be changed by two ways: Additive or subtractive. The primary function of these techniques is to modify the implant surface characteristics such as increasing bone formation to improve peri-implant osteogenesis, improvement of corrosion and wear resistance, and removal of surface contaminants. Following methods are used to change the surface topography of the implant.

\section{Machined surface}

The first generation of dental implants, termed the turned implants, had a relatively smooth surface after being manufactured. ${ }^{[21]}$ This surface is usually and inadequately called smooth since scanning electron microscopy analysis showed that they have grooves, ridges, and marks derived from tools used for their manufacturing which provides mechanical resistance through bone interlocking. ${ }^{[22]}$ However, the main disadvantage regarding the morphology of non-treated implants is the fact that osteoblastic cells are prone to grow along the grooves existing on the surface, which in terms of clinical implications means a longer healing time required. ${ }^{[23]}$ The machined implant is turned, milled, and polished. It is minimally rough, with a surface area roughness $(\mathrm{Sa})$ value of $0.3-1.0 \mu \mathrm{m} .^{[24]}$

\section{Sandblasting/grit blasting}

Sandblasting is one of the most commonly used types of surface modification processes because of its simplicity, low cost, and easiness of application. Microspheres of diameter in the range $10-540 \mu \mathrm{m}$ are typically accelerated toward the surface to be treated, using a compressed air or nitrogen blow. The main effect of sandblasting is to change the morphology of the treated surface, substantially increasing its roughness. The value of this parameter depends on several factors including: The type of grid material used the dimension of the spheres, the energy and angle when they hit the surface, and the duration of the treatment. Typical values of the Ra roughness are in the range $0.3-3 \mu \mathrm{m}$ as compared to Ra values lower than $0.1 \mu \mathrm{m}$ for polished Ti surfaces. A side effect of the sandblasting process is the contamination of the surface by the material released by the microspheres during their interaction with the surface. ${ }^{[25]}$ The grit blasting technique usually is performed with particles of silica (sand), alumina, titanium dioxide, or resorbable bioceramics such as calcium phosphate (CaP). Titanium oxide $\left(\mathrm{TiO}_{2}\right)$ particles with an average size of $25 \mu \mathrm{m}$ can produce moderately rough surfaces in the 1-2 $\mu \mathrm{m}$ range on dental implants. ${ }^{[9]}$

\section{Acid-etched surface}

The immersion of a titanium dental implant in strong acids such as hydrochloric acid, sulfuric acid, nitric acid, and hydrogen fluoride is another method of surface modification which produces micro pits on titanium surfaces with sizes ranging from 0.5 to $2 \mu \mathrm{m}$. The resulting surface shows a homogenous roughness, increased active surface area, and improved adhesion of osteoblastic lineage cells. Dual acid-etching consists in the immersion of titanium implants for several minutes in a mixture of concentrated $\mathrm{HCl}$ and $\mathrm{H}_{2} \mathrm{SO}_{4}$ heated above $100^{\circ} \mathrm{C}$ to produce a micro-rough surface ${ }^{[18]}$ that may enhance the osteoconductive process through the attachment of fibrin and osteogenic cells, resulting in bone formation directly on the surface of the implant.

\section{Grit blasting and acid etching (sandblasted and acid-etched [SLA])}

Following grit blasting, the surface is submitted to acid-etching to further enhance the topographic profile of the surface and remove processing by products. The advantages of this method include an increase in the total surface area of the implant, achieved due to the selective removal, resulting from electrochemical differences in the surface topography. ${ }^{[18]}$ This process should be carried out under controlled conditions, as over etching the surface decreases surface topography and mechanical properties and may be detrimental to osseointegration.

\section{Anodic oxidation}

To alter the topography and composition of the surface oxide layer of the implants, micro or nanoporous surfaces may also be produced by potentiostatic or galvanostatic anodization of titanium in strong acids, such as sulfuric acid, phosphoric acid, nitric acid, and hydrogen fluoride at high current density or potential. ${ }^{[26]}$ When strong acids are used in an electrolyte solution, the oxide layer will be dissolved along current convection lines and thickened in other regions which create micro or nanopores on the titanium surface. ${ }^{[27]}$ This electrochemical process results in an increased thickness and modified crystalline structure of the $\mathrm{TiO}_{2}$ layer. However, it is a complex procedure and depends on various parameters such as current density, concentration of acids, composition, and electrolyte temperature. ${ }^{[6]}$

\section{Laser treatment}

Studies showed that direct laser fabrication (DLF) implants have structures with complex geometry and could allow the better osteoconductive process. Evaluation of cytocompatibility and fibrin clot extension was carried out using osteoblasts and human blood to compare cell growth and fibrin clot covered areas on several implant surfaces. DLF implant surface showed lower cell density compared to machined, smooth textured grit blasted, 
and acid-etched implant surfaces. Inorganic acid etching slightly improved the extension of human blood to increase the micro roughness. Moreover, laser metal sintered implants were better adapted to the elastic properties of bone. Thereby, DLF implants could decrease stress-shielding effects and enhance implant longterm success rates. ${ }^{[28]}$

\section{Titanium plasma-spraying (TPS)}

TPS consists of injecting titanium particles into a plasma torch at high temperature. These particles are projected onto the surface of the implants where they were condensed and fuse together, forming a film about $30 \mu \mathrm{m}$ thick resulting in an average roughness of around $7 \mu \mathrm{m} .{ }^{[18]}$ The TPS processing may increase the surface area of dental implants up to approximately 6 times the initial surface area and is dependent on implant geometry and processing variables, such as initial powder size, plasma temperature, and distance between the nozzle output and target. ${ }^{[29]}$ One of the major concerns with plasma-sprayed coatings is the possible delamination of the coating from the surface of the titanium implant and failure at the implant-coating interface despite the fact that the coating is well-attached to the bone tissue. A major risk with high surface roughness concerns difficulties in controlling peri-implant it is due to the intercommunication between porous regions facilitates migration of pathogens to inner bone areas, potentially compromising the success of the implant therapy. ${ }^{[30]}$

\section{CaP coatings}

$\mathrm{CaP}$ coatings, mainly composed by hydroxyapatite (HA), have been used as a biocompatible, osteoconductive, and resorbable blasting materials. The idea behind the clinical use of HA is to use a compound with a similar chemical composition as the mineral phase of the bone to avoid connective tissue encapsulation and promote peri-implant bone apposition..$^{[31]}$ For this matter, the CaP coatings disclose osteoconductive properties allowing for the formation of bone on its surface by attachment, migration, differentiation, and proliferation of bone-forming cells. The hydroxyapatite ( $\mathrm{HA})$ ceramic particles are heated to extremely high temperatures and deposited at a high velocity onto the metal surface where they condense and fuse together forming a 20-50 $\mu \mathrm{m}$ thick film. ${ }^{[32]}$

To improve coatings, a number of techniques have been developed with the aim of producing thin-film nanostructured bio-ceramic coatings, such as sol-gel deposition, pulsed laser deposition, sputtering coating techniques, electrophoretic deposition, and ion-beam-assisted deposition. ${ }^{[33]}$ The sol-gel electrophoresis method can be prepared using a dip coating or a spin coating process and is capable of improving chemical homogeneity in the resulting HA coating as it allows for better control of the chemical composition and macrostructure of the coating. ${ }^{[6]}$ The Pulsed Laser Deposition results in a titanium surface microstructures with greatly increased hardness, corrosion resistance, and high degree of purity with standard roughness and thicker oxide layer. The ion-beam assisted deposition technology permits the formation of thin films at atomic and molecular levels, as well as low temperature syntheses utilizing ionic effects. ${ }^{[34,35]}$ Recurrent drawbacks include controlling the calcium-phosphate layer composition, resorbability, weak adhesion to the substrates, the use of high temperatures, or the costs involved in the process. In fact, there are several reports of cracking and/or delamination of the coating due the generation of large thermal stresses during processing, which may affect the quality and rate of peri-implant bone formation. ${ }^{[36]}$

\section{Biomimetic CaP coatings}

Biomimetic coatings involve the use of microstructures and functional domains of organismal tissue function to deposit $\mathrm{CaP}$ on medical devices to improve their biocompatibility. ${ }^{[37]}$ This bioinspired method consists in the precipitation of CaP apatite crystals onto the dental implant surface through simulated body fluids under near-physiological or biomimetic conditions of temperature and $\mathrm{pH}^{[37]}$

\section{Biological Interactions of Implant Surfaces Modified by Different Methods on Intra-oral Tissues}

\section{Turned/machined}

Studies on animal models and clinical studies have suggested a positive correlation between the implant surface roughness and bone-implant contact (BIC). The success rate of machined (nontreated) implants has been reported as less when placed in low bone density compared to good bone quality. ${ }^{[38]}$ Osteoblasts are rugophilic, hence, they tend to grow along the grooves existing on the implant surface. The disadvantage regarding the morphology of non-treated implants is that they provide mechanical resistance for bone interlocking. According to a study ${ }^{[39]}$ proposed by Sennerby et al. healing process in round screw-shaped machined Ti implants in cortical bone after 3-180 days. They reported an early cellular response, a relative absence of inflammatory cells and a rapid formation of woven bone from the endosteal surface.

\section{Acid-etched}

Acid-etched implant surface produces a microtexture rather than a macrotexture. The dual acid etched surfaces improve the osteoconductive process through the attachment of fibrin and osteogenic cells, enhancing bone formation directly on the implant surface. ${ }^{[40]}$ When a higher temperature is used with an acid etching method, they produce a homogeneous microporous surface with increased cell adhesion and greater BIC compared to TPS surfaces. ${ }^{[41]}$ In vitro reports, on cell response to hydrophilic SLA, osteoblasts behavior was affected by altering protein absorption that directly induced differentiation by the assembly of focal adhesion sites (FAs) and intracellular four signaling cascade activation. The FAs are important sites of signaling that control spreading, migration, cytoskeletal organization, cell cycle progression, gene expression, and matrix fibrillogenesis. ${ }^{[42]}$

\section{Laser sintering}

Laser-sintered $\mathrm{Ti}$ implants showed high purity with enough roughness for good osseointegration compared to other treatments. Biological evaluation of the role of $\mathrm{Ti}$ ablation and chemical properties showed the ability of its grooved surface to orientate osteoblasts attachment and control the direction of ingrowth. ${ }^{[43]}$

\section{CaP coating}

Coating of dental Ti implants with CaP ceramic is commonly used to change the chemical composition of the implant surface. 
After implant placement, the CaP particles are released into the peri-implant region; raising the saturation of body fluids and leading to the precipitation of a biological apatite onto the implant surface. Endogenous proteins present in this layer of biological apatite act as a matrix for osteogenic cell attachment and growth. Integrins mediate the cellular interactions with the apatite layer and its proteins onto the implant surface. The signaling pathways through integrins can regulate bone forming cell activity. The bone stimulating action of $\mathrm{CaP}$ coatings at implant surface enhances early osseointegration compared to non-CaP coated dental implants. ${ }^{[44,45]}$

\section{HA coating}

Several methods have been used for applying HA coatings on to metals, and each method can result in different material properties. Plasma spraying that forms a coating thickness of $40-50 \mu \mathrm{m}$ is the most common used technique for coating Ti implants. A synthetic form of HA has a similar chemical composition to the mineral matrix of bone. ${ }^{[46]} \mathrm{HA}$ can form a direct and strong bone-to-implant bond. After implant placement, $\mathrm{HA}$ acts as a bioactive material where a sequence of events results in precipitation of a $\mathrm{CaP}$ rich layer on the implant surface. The CaP incorporated layer will be developed in a biologically equivalent $\mathrm{HA}$ that will be incorporated in the developing bone through octacalcium phosphate. ${ }^{[47]}$ In many preclinical and clinical studies calcium-to-phosphate ratio, phase composition and crystal structure are used as chemical parameters, to optimize the performance of $\mathrm{CaP}$ coatings. ${ }^{[17]} \mathrm{HA}$ coatings showed a persistent significant improvement of the osteoconductivity of metallic implants.

\section{Growth factors coating}

Implant surfaces can be coated with biomolecules, such as bioadhesive or growth factors, to promote osseointegration. The arginylglycylaspartic acid (RGD) sequence from fibronectin is the most common used bio-adhesive that binds to adhesion receptors and promotes cell adhesion. RGD functionalized and tissue engineered constructs that can improve early bone ingrowth and matrix mineralization in vivo. ${ }^{[48,49]}$ However, $\mathrm{BIC}$ and osteoblast differentiation were not improved by RGD application to Ti implant surfaces. This might be due to the absence of crucial modulatory domains from the native fibronectin, the RGD signals disappear by non-specific adsorption of plasma protein and interactions with inflammatory components. On the other hand, Germanier et $a l^{[50]}$ compared sandblasted implant surfaces that were either RGD peptide polymer coated or uncoated and placed in the maxillae of minipigs. They concluded that RGD coating might enhance bone apposition at the early stages of bone regeneration. Platelet-derived growth factor (PDGF) and insulin-like growth factor (IGF) were used in combination around implants where they can produce $2-3$ times more new bone within 7 days compared to controls. However, after 21 days, in spite of a large volume of new bone formed around dental implants treated with growth factors, there was no significant difference between growth factor and control sites. Thus, the use of PDGF/IGF may only accelerate the process of bone formation. ${ }^{[51]}$

\section{Electrochemical anodization}

The electrochemical anodization can produce a mixed nano/submicron scale $\mathrm{TiO}_{2}$ network layer (lateral pore size:
20-160 $\mathrm{nm}$ ) on a polished Ti surface in $10 \mathrm{~min}$. This $\mathrm{TiO}_{2}$ network layer improved the whole blood coagulation and human bone marrow stem cell adhesion on a Ti dental implant surface. ${ }^{[52]}$ The galvanic anodization of $\mathrm{Ti}$ in strong acids produces a thick layer of $\mathrm{TiO}_{2}$. Burgos et al. compared implant surface manufactured by anodic oxidation to turned surfaces in a rabbit model. BIC values were $20 \%, 23 \%$, and $46 \%$ around the oxidized surfaces with a different osseointegration pattern, while 15\%, 11\%, and $26 \%$ around the machined surfaces, after 7,14 , and 28 days, respectively. Huang et al. studied the oxidized implant surfaces placed in the posterior maxilla. After 16 weeks, the recorded mean of BIC was $74 \%$. They stated that this oxidized surface showed a considerable osteoconductive potential resulting in a high level of implant osseointegration in Type IV bone. ${ }^{[53]}$

\section{Fluoride treatment}

Ti can react to fluoride $(\mathrm{F})$ ions, forming soluble $\mathrm{TiF}^{[4]}$ that enhances osseointegration of dental implants. The analysis of human mesenchymal cells showed no difference in cell attachment between the fluoride treated and control grit-blasted implants. Fluoridated implants also sustained greater push-out forces and showed higher removal torque than control implants. In addition, it increased osteoblast differentiation represented by increased expression of Cbfa1, osterix, and bone sialoprotein. ${ }^{[54]}$

\section{Biologically active drugs}

Bisphosphonate coated Ti implants improved local bone density in the peri-implant region, due to its antiresorptive effect limited to the implant site. Du et al. ${ }^{[55]}$ studied the effect of simvastatin, by oral administration, on implant osseointegration in osteoporotic rats and showed that it can enhance implant osseointegration. Tetracycline- $\mathrm{HCl}$ has the ability to kill microorganisms that may contaminate the implant surface and can remove the smear layer and endotoxins from the implant surface. In addition, it prevented the action of collagenase, increased cell proliferation, attachment, and bone healing, improved blood clot attachment, and retention on the implant surface during the early phase of healing, thus enhanced osseointegration. ${ }^{[56]}$

\section{TPS}

Al-Nawas et al. ${ }^{[57]}$ compared different types of macro and microstructure implant surfaces in dogs. After 8 weeks of healing and 3 months of loading, higher BIC values of TPS rough surfaces and blasted/acid-etched implants were reported in comparison to machined ones. The difference between the TPS and the blasted/ acid-etched implants BIC values was not significant. An in vivo study ${ }^{[58]}$ that evaluated TPS versus plasma sprayed HA implants, showed that bone contact length for HA implants was significantly higher than TPS at 12 weeks of implant placement and 1 year of loading.

\section{Alkali treatment}

$\mathrm{NaOH}$ treatment includes the formation of a bioactive sodium titanate layer on orthopedic Ti surfaces. Following the immersion in stimulated body fluids (SBF), bone-like apatite is deposited onto this layer. Sodium ions in the titanate layer are exchanged with $\mathrm{H}_{3} \mathrm{O}^{+}$ions from the SBF forming $\mathrm{Ti}-\mathrm{OH}$ groups, which combine with 
$\mathrm{Ca}^{2+}$ ions to produce amorphous calcium titanate. The reaction with phosphate polyatomic ions forms amorphous $\mathrm{CaP}$, which transforms into bone-like apatite. Alkali treatment and biomimetic precipitation of $\mathrm{CaP}$ coatings are techniques that can be used to coat the interior of porous metallic surfaces. ${ }^{[59,60]}$

\section{Future Trends and Conclusion}

Microtopography of the implant surface in contact with the biologic tissues is recognized to play a fundamental role in the healing process, but the exact mechanism underlying the osseointegration process remains poorly understood. Within the time frame of the present review, there has been number of dental implants commercially available with a wide variety of surface characteristics, both in terms of structural and chemical properties. Most of the in vivo and in vitro studies showed several novel dental implant surfaces, mostly consisting in modifications of the commercially available ones. One of the main drawbacks in the dental implant surface is the empirical nature of the manufacturing process as it lacks of consensus in the choice of uniform standard for obtaining controlled topographies. For this matter, several in vivo and in vitro studies are required, but often performed without a hierarchical approach and standardized parameters using different surfaces, cell populations, or animal models.

There is an urgent need for more fundamental research in this area that would normalize and combine both in vitro and in vivo studies ultimately leading to the appropriate clinical application. A large amount of studies compare a specific rough surface with machined or turned surfaces as a control group. Since it is widely acknowledge that rough surfaces have better performance than machined or turned surfaces, the results have typically the tendency to be positive. Therefore, the inclusion of a widely accepted positive control would be beneficial to evaluate the performance of a certain surface in a more realistic way. Clinical trials comparing different commercially available implant surfaces under similar clinical situations are rarely disclosed, making the outcome assessment between different surfaces quite difficult.

\section{References}

1. Branemark PI, Hansson BO, Adell R, Breine U, Lindström J, Hallén O, et al. Osseointegrated implants in the treatment of the edentulous jaw. Experience from a 10-year period. Scand J Plast Reconstr Surg Suppl 1977;16:1-132.

2. Albrektsson $\mathrm{T}$, Brånemark $\mathrm{Pl}$, Hansson $\mathrm{HA}$, Lindström J. Osseointegrated titanium implants. Requirements for ensuring a long-lasting, direct bone-to-implant anchorage in man. Acta Orthop Scand 1981;52:155-70.

3. Jokstad A, Braegger U, Brunski JB, Carr AB, Naert I, Wennerberg A, et al. Quality of dental implants. Int Dent J 2003;53(6 Suppl 2):409-43.

4. Kasemo B, Gold J. Implant surfaces and interface process. Adv Dent Res 1999;13:8-20.

5. Puleo DA, Thomas MV. Implant surfaces. Dent Clin N Am 2006;50:323-38.

6. Anil S, Anand PS, Alghamdi H, Jansen JA. Dental Implant Surface Enhancement and Osseointegration. London: IntechOpen; 2011.

7. Wennerberg A, Albrektsson T. Suggested guidelines for the topographic evaluation of implant surfaces. Int J Oral Maxillofac Implants 2000;15:331-44.

8. Bango A, Di Bello C. Surface treatments and roughness properties of Ti-based materials. J Mater Sci Mater Med 2004;15:935-49.

9. Coelho PG, Granjeiro JM, Romanos GE, Suzuki M, Silva NR,
Cardaropoli G, et al. Basic research methods and current trends of dental implant surfaces. Biomed Mater Res B Appl Biomater 2009;88B:579-96.

10. Stanford CM. Surface modification of biomedical and dental implants and the process of inflammation, wound healing and bone formation. Int J Mol Sci 2010;11:354-69.

11. Malvin ER. Dentistry: An Illustrated History. $2^{\text {nd }}$ ed. New York: Abradale Press; 1985.

12. Greenfield EJ. Implantation of artificial crown and bridge abutments. Int J Oral Implant 1991;7:63-8.

13. Linkow LI, Dorfman JD. Implantology in dentistry: A brief historical perspective. NY State Dent J 1991;57:31-5.

14. Branemark PI, Zarb G, Albrektsson T. Tissue-Integrated Prostheses: Osseointegration in Clinical Dentistry. Chicago: Quintessence Publishing; 1985.

15. Leney WR. In recognition of an implant pioneer: Professor Dr. Andre Schroeder. Int J Oral Maxillofac Implants 1993;8:135-6.

16. Steinemann SG. Titanium--the material of choice? Periodontol 2000 1998;17:7-21.

17. Palmquist A, Omar OM, Esposito M, Lausmaa J, Thomsen P. Titanium oral implants: Surface characteristics, interface biology and clinical outcome. J R Soc Interface 2010;7 Suppl 5:S515-27.

18. Le Guehennec L, Soueidan A, Layrolle P, Amouriq Y. Surface treatments of titanium dental implants for rapid osseointegration. Dent Mater 2007;23:844-54.

19. Elias CN, Oshida Y, Lima JH, Muller CA. Relationship between surface properties (roughness, wettability and morphology) of titanium and dental implant removal torque. J Mech Behav Biomed Mater 2008;1:234-42.

20. Anselme K, Bigerelle M. Topography effects of pure titanium substrates on human osteoblast long-term adhesion. Acta Biomater 2005;1:211-22.

21. Branemark PI, Adell R, Breine U, Hansson BO, Lindstrom J, Ohlsson A. Intraosseous anchorage of dental prostheses. I. Ex-perimental studies. Scand J Plast Reconstr Surg 1969;3:81-100.

22. Aldosari AA, Anil S, Alasqah M, AI Wazzan KA, Al Jetaily SA, Jansen JA. The Influence of implant geometry and surface composition on bone response. Clin Oral Implants Res 2013;25:500-5.

23. Anil S, Anand PS, Alghamdi H, Jansen JA. Dental implant surface enhancement and osseointegration. In: Implant Dentistry a Rapidly. Toronto, Canada: Envolv; 2011.

24. Ting M. Classification and effects of implant surface modification on the bone: Human cell based in vitro studies. J Oral Implantol 2016;43:58-83.

25. Mandracci P, Mussano F, Rivolo P, Carossa S. Surface treatments and functional coatings for biocompatibility improvement and bacterial adhesion reduction in dental implantology. Coatings 2016;6:3390.

26. Klein MO, Al-Nawas B. For which clinical indications in dental implantology is the use of bone substitute materials scientifically substantiated? Eur J Oral Implantol 2011;4:11-29.

27. Sul YT, Johansson C, Wennerberg A, Cho LR, Chang BS, Albrektsson T. Optimum surface properties of oxidized implants for reinforcement of osseointegration: Surface chemistry, oxide thickness, porosity, roughness, and crystal structure. Int J Oral Maxillofac Implants 2005;20:349-59.

28. El-Gammal YM, El-Gammal YN, Fadhil NO, Maria MO. Biological reactions to different dental implant surface treatments. Int J Contemp Dent Med Rev 2016;2016:051015.

29. Massaro C, Rotolo P, De Riccardis F, Milella E, Napoli A, Wieland M, et al. Comparative investigation of the surface properties of commercial titanium dental implants. Part I: Chemical composition. J Mater Sci Mater Med 2002;13:535-48.

30. Mombelli A, Muller N, Cionca N. The epidemiology of peri-implantitis. Clin Oral Implants Res 2012;23 Suppl 6:67-76.

31. Von Wilmowsky C, Moest T, Nkenke E, Stelzle F, Schlegel KA. Implants in bone: Part I. A current overview about tissue response, 
surface modifications and future perspectives. Oral Maxillofac Surg 2013;18:243-57.

32. Mendonca G, Medonca SB, Pagotto GL. Nanostructured aluminacoated implant surface: Effect on osteoblast related gene expression and bone to implant contact in vivo. Int J Oral Maxillofac Implants 2009;24:205-6.

33. Granato R, Marin C, Suzuki M, Gil JN, Janal MN, Coelho PG. Biomechanical and histomorphometric evaluation of a thin ion beam bioceramic deposition on plateau root form implants: An experimental study in dogs. J Biomed Mater Res B Appl Biomater 2009;90:396-403.

34. Gaggl A, Schultes G, Müller WD, Kärcher H. Scanning electron microscopical analysis of laser-treated titanium implant surfaces--a comparative study. Biomaterials 2000;21:1067-73.

35. Hanawa T. A comprehensive review of techniques for biofunctionalization of titanium. J Periodontal Implant Sci 2011;41:263-72.

36. Botos S, Yousef $H$, Zweig B, Flinton R. The effect of microtexturing of the dental implant collar on crestal bone levels and peri-implnat health. Int J Oral Maxillofac Implants 2011;26:492-8.

37. Schliephake H, Scharnweber D, Roesseler S, Dard M, Sewing A, Aref A. Biomimetic calcium phosphate composite coating of dental implants. Int J Oral Maxillofac Implants 2006;21:738-46.

38. Junker R, Dimakis A, Thoneick M, Jansen JA. Effects of implant surface coatings and composition on bone integration: A systematic review. Clin Oral Implants Res 2009;20 Suppl 4:185-206.

39. Wennerberg A, Albrektsson T. On implant surfaces: A review of current knowledge and opinions. Int J Oral Maxillofac Implants 2010;25:63-74.

40. Orsini G, Assenza B, Scarano A, Piattelli M, Piattelli A. Surface analysis of machined versus sandblasted and acidetched titanium implants. Int J Oral Maxillofac Implants 2000;15:779-84.

41. Novaes AB Jr., de Souza SL, de Barros RR, Pereira KK, lezzi G, Piattelli A. Influence of implant surfaces on osseointegration. Braz Dent J 2010;21:471-81.

42. Abbi S, Guan JL. Focal adhesion kinase: Protein interactions and cellular functions. Histol Histopathol 2002;17:1163-71.

43. Frenkel SR, Simon J, Alexander H, Dennis M, Ricci JL. Osseointegration on metallic implant surfaces: Effects of microgeometry and growth factor treatment. J Biomed Mater Res 2002;63:706-13.

44. de Groot K, Wolke JG, Jansen JA. Calcium phosphate coatings for medical implants. Proc Inst Mech Eng H 1998;212:137-47.

45. Daculsi G, Laboux O, Malard O, Weiss P. Current state of the art of biphasic calcium phosphate bioceramics. J Mater Sci Mater Med 2003;14:195-200.

46. Ducheyne P, Cuckler JM. Bioactive ceramic prosthetic coatings. Clin
Orthop Relat Res 1992;102-14.

47. Ogiso M, Tabata T, Ichijo T, Borgese D. Examination of human bone surrounded by a dense hydroxyapatite dental implant after longterm use. J Long Term Eff Med Implants 1992;2:235-47.

48. Alsberg E, Anderson KW, Albeiruti A, Franceschi RT, Mooney DJ. Cellinteractive alginate hydrogels for bone tissue engineering. J Dent Res 2001;80:2025-9.

49. Lutolf MP, Weber FE, Schmoekel HG, Schense JC, Kohler T, Muller R, et al. Repair of bone defects using synthetic mimetics of collagenous extracellular matrices. Nat Biotechnol 2003;21:513-8.

50. Malvin ER. Dentistry: An Illustrated History. $2^{\text {nd }}$ ed. New York: Abradale Press; 1985.

51. Becker W, Lynch SE, Lekholm U, Becker BE, Caffesse R, Donath K, et al. A comparison of ePTFE membranes alone or in combination with platelet-derived growth factors and insulinlike growth factor-I or demineralized freeze-dried bone in promoting bone formation around immediate extraction socket implants. J Periodontol 1992;63:929-40.

52. Chiang CY, Chiou SH, Yang WE, Hsu ML, Yung MC, Tsai ML, et al. Formation of $\mathrm{TiO}(2)$ nano-network on titanium surface increases the human cell growth. Dent Mater 2009;25:1022-9.

53. Huang $\mathrm{YH}$, Xiropaidis AV, Sorensen RG, Albandar JM, Hall J, Wikesjo UM. Bone formation at titanium porous oxide (TiUnite) oral implants in Type IV bone. Clin Oral Implants Res 2005;16:105-11.

54. Cary LA, Guan JL. Focal adhesion kinase in integrin-mediated signaling. Front Biosci 1999;4:D102-13.

55. Du Z, Chen J, Yan F, Xiao Y. Effects of Simvastatin on bone healing around titanium implants in osteoporotic rats. Clin Oral Implants Res 2009;20:145-50.

56. Yang F, Zhao SF, Zhang F, He FM, Yang GL. Simvastatin-loaded porous implant surfaces stimulate preosteoblasts diff erentiation: An in vitro study. Oral Surg Oral Med Oral Pathol Oral Radiol Endod 2011;111:551-6.

57. Al-Nawas B, Groetz KA, Goetz H, Duschner H, Wagner W. Comparative histomorphometry and resonance frequency analysis of implants with moderately rough surfaces in a loaded animal model. Clin Oral Implants Res 2008;19:1-8.

58. Ong JL, Carnes DL, Bessho K. Evaluation of titanium plasmasprayed and plasma-sprayed hydroxyapatite implants in vivo. Biomaterials 2004;25:4601-6.

59. Kim HM, Kokubo T, Fujibayashi S, Nishiguchi S, Nakamura T. Bioactive macroporous titanium surface layer on titanium substrate. J Biomed Mater Res 2000;52:553-7.

60. Nishiguchi S, Kato H, Neo M, Oka M, Kim HM, Kokubo T, et al. Alkali and heat-treated porous titanium for orthopaedic implants. J Biomed Mater Res 2001;54:198-208. 